\title{
Influence of slag on leaching behavior of cement mortar lined in ductile iron pipe under a flowing solution
}

\author{
Yu-Juan Tang, Xiao-Bao Zuo* , Guang-Ji Yin, Shao-Li He, Olawale Ayinde \\ Department of Civil Engineering, Nanjing University of Science \& Technology, Nanjing, 210094, P.R.China
}

\begin{abstract}
In order to investigate the influence of slag on the leaching behavior of cement mortar lined in ductile iron pipe in a flowing solution, two types of ductile iron pipe specimens lined with ordinary- and $40 \%$ slag- cement mortar are firstly prepared, then, an accelerated leaching experiment on the prepared specimens is carried out by using a $6 \mathrm{M}$ ammonium chloride solution at a flow rate of $0.3 \mathrm{~m} / \mathrm{s}$. The parameters of linings at different leaching times, such as porosity, pore size distribution, phase composition and Calcium-Silicon $(\mathrm{Ca} / \mathrm{Si})$ ratio, were analyzed by using the saturation-drying weighing method, mercury intrusion porosimetry (MIP), X-ray diffraction (XRD) and scanning electron microscopy in back scattered electron mode (ESEM-BSE) measurements. Results show that, the mixture of $40 \%$ slag in cement-mortar lining can reduce its initial porosity and Calcium-Silicon ratio, and improve its pore size distribution and phase composition. In the accelerated leaching process, the porosity, phase composition and Calcium-Silicon ratio of the slag-cement-mortar lining with $40 \%$ slag have smaller change than that of the ordinary-cement-mortar lining without slag, and it indicates that the addition of slag can effectively improve the calcium leaching resistance of cement-mortar lining in ductile iron pipes in water supply engineering.
\end{abstract}

Keywords: Slag; cement-mortar lining; calcium leaching; ductile iron pipe; flowing solution

\section{Introduction}

Ductile iron pipes lined with cement-mortar protective layer in their inner wall by the centrifugal process $[1,2]$ have been widely used in water supply and drainage engineering because of their large diameter, high bearing capacity, good durability and safe operation when buried deeply in underground [1-6]. However, when the soft water with low hardness (e.g. tap water and desalinated seawater) is carried by the cementmortar-lined ductile iron pipe, it easily results in the calcium leaching of cement-mortar lining in the pipe, namely, the dissolution of calcium hydroxide $(\mathrm{CH})$ and decalcification of calcium silicate hydrate(C-S-H) gel [7]. The calcium leaching causes not only the deterioration of microstructure and decrease in strength of the lining cement mortar but also the reduction of alkalinity in pore solution of mortar, which can lead to the depassivation of the ductile iron[1, 2, 8-11]. Thus, the calcium leaching caused by flowing water will gradually reduce the protective effect of cement-mortar lining on ductile iron pipes, and also reduce the durability and in-service lifetime of cement-mortar-lined ductile iron pipe [1, 2]. Design of cement-mortar lining with an excellent leaching resistance is of great importance to improve the durability of ductile iron pipes in water supply.

The blast furnace slag can effectively change the microstructure of cement-based materials and the phase composition of cement hydrated products, while enhancing its calcium leaching resistance in water environment [12-14]. Related studies have been conducted by many researchers [7, 12-14]. Taylor[12] used Scanning Electron Microscope(SEM) to analyze the microstructure evolution of slag-cement pastes cured in water for 20 years, and reported that the calcium hydroxide content has a gradual decrease while the

\footnotetext{
${ }^{*}$ Corresponding author. Tel: +86 2584315773.

E-mail: xbzuo@sina.com (Xiao-Bao Zuo).
} 
hydration degree of slag has a slight increases in the slag-cement matrix. Liu [14] utilized SEM for observing the microstructure morphology of leached slag-cement pastes under the attack of flowing deionized water, and also analyzed the evolution characteristics of its microstructure in the long-term process of leaching. Jain et al. [13] investigated the changes of the porosity and calcium hydroxide content in plain and slag- and fly ash-modified cement pastes in pure water with the leaching time by the weighting and thermogravimetric methods respectively, and it can be obtained that, with the addition of slag and fly ash, the microstructure of specimens became more dense and the $\mathrm{Ca}-\mathrm{Si}$ molar ratio became lower, while the slag-modified cement pastes showed better leaching resistance than the plain paste. However, because the natural calcium leaching in water is a very slow process, some accelerated leaching tests have been conducted to investigate the influence of calcium leaching on cement-based materials' performance [15-19]. Yang et al. [16] used 6M ammonium chloride solution to accelerate the calcium leaching of cement pastes and investigated the influence of leaching on its mechanical properties, such as the hardness and compressive strength. Wan [19] experimentally investigated the equilibrium curve of Ca in 6M ammonium nitrate solution to clarify the accelerated leaching mechanism in cement-based materials, and it can be obtained from comparison with the equilibrium curve in water that their dissolution and leaching mechanisms are similar.

The current researches reveal the influence of slag on hydration characteristics, microstructure evolution and leaching mechanism of cement-based materials in water environments or accelerated solutions, and further demonstrate that the mixture of slag in cement mortar can improve its calcium leaching resistance in water environment. However, the cement-mortar lining in ductile iron pipe produced by the centrifugal process has two components, namely cement paste and mortar, which have greatly gradient distributions of microstructure and compositions. Therefore, the leaching behavior of the specimen of cement-mortar lining should be different from that of the ordinary mortar specimen. But, very limited study has been conducted on the leaching behavior of cement mortar lined in ductile iron pipe under flowing water, and there is hardly any substantial design basis for the durability improvement of cement-mortar lining by the mixture of slag in ductile iron pipe.

In this paper, two kinds of specimens of ductile iron pipes, lined with ordinary- and $40 \%$ slag- cement mortar, are designed and produced to carry out the accelerated leaching experiment for investigating their leaching behavior under the flowing solution. Some measurements such as the saturation-drying weighing method, MIP, XRD and ESEM-BSE are used to analyze the influence of slag on the calcium leaching process of the cement-mortar lining with/without slag in ductile iron pipe.

\section{Experiments}

\subsection{Materials}

The cement used in this study was the 52.5-grade ordinary portland cement (P.O 52.5), whose chemical compositions are listed in Table 1, with a density of $3150 \mathrm{~kg} / \mathrm{m}^{3}$ and specific surface area of $369.6 \mathrm{~m}^{2} / \mathrm{kg}$. The initial and final setting times are $72 \mathrm{~min}$ and 290min respectively, while its normal compression strength and flexural strength for 28days curing are 60.5MPa and 8.7MPa respectively. S95-grade blast furnace slag powder with a density of $2900 \mathrm{~kg} / \mathrm{m}^{3}$ and specific surface area of $435 \mathrm{~m}^{2} / \mathrm{kg}$ was used as an additive mixture. River sand with a fineness modulus of 2.44 , apparent density of $2600 \mathrm{~kg} / \mathrm{m}^{3}$ and water content of $3.6 \%$ was used. Tap water and purified water were respectively used to mix the slag-cement pastes and prepare the ammonium chloride solution. Table 2 lists the mixture proportions of the slag- and ordinary- cement mortar linings. 
Table 1

Characteristic of cementitious materials

\begin{tabular}{cccccccccccc}
\hline \multirow{2}{*}{ Material } & \multicolumn{4}{c}{ Chemical composition (\%) } & \multicolumn{4}{c}{ Compound composition of clinker (\%) } \\
& $\mathrm{SiO}_{2}$ & $\mathrm{Al}_{2} \mathrm{O}_{3}$ & $\mathrm{Fe}_{2} \mathrm{O}_{3}$ & $\mathrm{CaO}$ & $\mathrm{MgO}$ & $\mathrm{SO}_{3}$ & $\mathrm{C}_{3} \mathrm{~S}$ & $\mathrm{C}_{2} \mathrm{~S}$ & $\mathrm{C}_{3} \mathrm{~A}$ & $\mathrm{C}_{4} \mathrm{AF}$ & Total \\
\hline Cement & 21.10 & 5.56 & 3.98 & 62.48 & 1.76 & 2.59 & 55.10 & 19.10 & 6.50 & 8.50 & 89.20 \\
Slag & 32.70 & 16.10 & 5.54 & 38.70 & 5.50 & 1.46 & - & - & - & - & \\
\hline
\end{tabular}

Table 2

Mixture proportions of slag- and ordinary- cement mortar linings.

\begin{tabular}{cccccc}
\hline Species & \multirow{2}{*}{ Water-binder ratio } & \multicolumn{2}{c}{ Mass fraction/\% } \\
& & cement & slag & sand & water \\
\hline Slag-cement mortar lining & 0.4 & 60 & 40 & 130 & 40 \\
Ordinary cement-mortar lining & 0.4 & 100 & 0 & 130 & 40 \\
\hline
\end{tabular}

Ammonium chloride reagent with a solubility of $37.2 \mathrm{~g} / 100 \mathrm{ml}$ at room temperature was used to prepare the accelerated leaching solution with the concentration of $6 \mathrm{M}$. Similar to the accelerated leaching mechanism of ammonium nitrate solution, the ammonium chloride solution can be also used to perform the chemically accelerated leaching on cement-based materials to reveal its leaching mechanism in a relatively short time[16, 20, 21], and the accelerated leaching principle is to promote chemical reaction between calcium hydroxide and ammonium chloride in the leachant solution, forming gaseous ammonia and calcium chloride, which is highly soluble in water (see Eq. (1)) [16].

$$
\begin{aligned}
\mathrm{Ca}(\mathrm{OH})_{2}+2 \mathrm{NH}_{4} \mathrm{Cl} & =\mathrm{Ca}^{2+}+2 \mathrm{OH}^{-}+2 \mathrm{H}^{+}+2 \mathrm{NH}_{3}(\uparrow)+2 \mathrm{Cl}^{-} \\
& =\mathrm{CaCl}_{2}+2 \mathrm{NH}_{3}(\uparrow)+2 \mathrm{H}_{2} \mathrm{O}
\end{aligned}
$$

\subsection{Preparation of specimens}

The cement-mortar-lined ductile iron pipe specimen was produced by the centrifugal process [3], as follows: the cement mortar was firstly prepared according to the mixture proportion in Table 2, and then injected into the ductile iron pipe. Next, the ductile iron pipe with the injected cement mortar was installed on the centrifugal machine with an operating speed of $2600 \mathrm{rpm}$. After the revolutions lasting 5 minutes, the injected cement mortar was evenly spread along the inner wall of the ductile iron pipe under the centrifugal force, and the extra water produced by the centrifugal process was discharged, so it results in the reduction of the water-cement (binder) ratio of cement-mortar lining, and its actual water-cement (binder) ratio is 0.3 by the measurement on the extra water.

Afterwards, the prepared cement-mortar-lined ductile iron pipe specimen was put into the curing room, and began to cure according to the following steps [22]: Firstly, the specimen was naturally cured in the curing room for 2 hours while the temperature was kept at $25^{\circ} \mathrm{C}$; Secondly, the steam with the moisture of $90 \%$ was filled in the room for curing the specimen while the temperature was raised from $25^{\circ} \mathrm{C}$ to $60^{\circ} \mathrm{C}$ by heating for 4 hours, and then continue to cure for 4 hours at $60^{\circ} \mathrm{C}$. Finally, the heating was stopped, and the specimen was naturally cooled for an hour again, so the cement-mortar-lined ductile iron pipe specimen was completed, as shown in Fig.1(a). Fig.1(b) shows the stratification of cement-mortar lining in the pipe, and a cross-sectional view of cement-mortar lining in ductile iron pipe is presented in Fig.1(c). Table 3 lists the structural parameters of the cement-mortar-lined ductile iron pipe for the leaching experiment. 

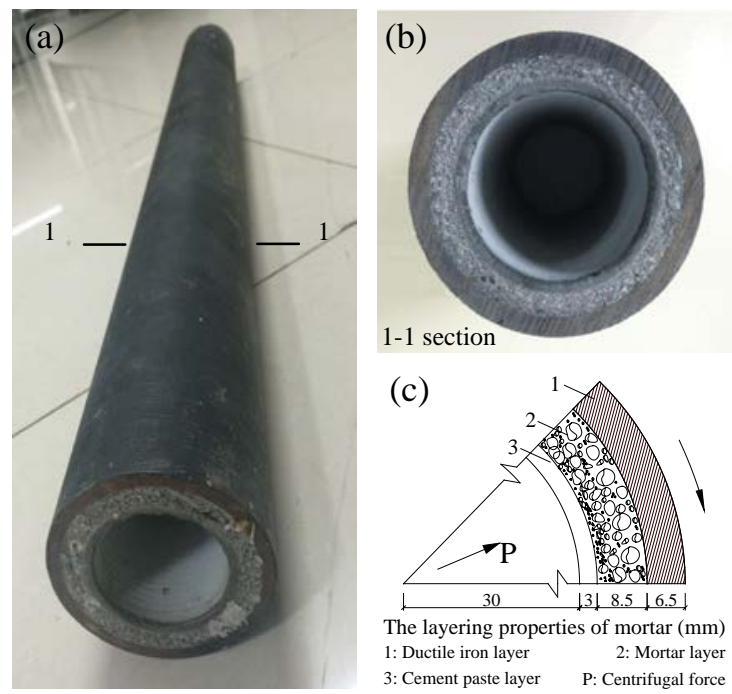

Fig.1 Cement-mortar-lined ductile iron pipe

Table 3

112 Structural parameters of the cement-mortar-lined ductile iron pipe (mm)

\begin{tabular}{ccccccc}
\hline Specimen & $\begin{array}{c}\text { Length of } \\
\text { ductile } \\
\text { iron pipe }\end{array}$ & $\begin{array}{c}\text { Internal } \\
\text { diameter }\end{array}$ & $\begin{array}{c}\text { External } \\
\text { diameter }\end{array}$ & $\begin{array}{c}\text { Thickness } \\
\text { of cement } \\
\text { paste layer }\end{array}$ & $\begin{array}{c}\text { Thickness } \\
\text { of mortar } \\
\text { layer }\end{array}$ & $\begin{array}{c}\text { Thickness } \\
\text { of cast iron } \\
\text { layer }\end{array}$ \\
\hline $\begin{array}{c}\text { Slag-cement-mortar-lined ductile iron pipe } \\
\text { Ordinary-cement-mortar-lined ductile iron pipe }\end{array}$ & 1000.0 & 60.0 & 96.0 & 3.0 & 8.5 & 6.5 \\
\hline
\end{tabular}

\subsection{Experimental method}

\subsubsection{Experimental setup}

An experimental setup for performing the accelerated corrosion of the cyclically flowing water on the specimen was designed, as shown in Fig.2. It is made up of a cement-mortar-lined ductile iron pipe with a length of $1.0 \mathrm{~m}$, a plastic container with $6 \mathrm{M}$ ammonium chloride solution of $130 \mathrm{~L}$, a corrosion-resistant pump with a power of $12 \mathrm{~W}$, a temperature controller and some connecting plastic tubes of diameter $25 \mathrm{~mm}$ each. The specimen and pump were connected with the plastic tubes and placed together in a closed container to form the cyclic water transportation system. The flowing rate of ammonium chloride solution in the specimen is $0.3 \mathrm{~m} / \mathrm{s}$, and maintained at a temperature of $25^{\circ} \mathrm{C}$ inthe plastic container. The ammonium chloride solution is renewed once every 150 days.

\subsubsection{Accelerating factor}

In order to use the experimental results of accelerated corrosion on the specimen to further evaluate the performance of the cement-mortar-lined ductile iron pipe in actual water transportation, the accelerated and conventional leaching experiments of cement-mortar lining specimens in 6M ammonium chloride solution and purified water were respectively completed [23], and the leaching depth characterizing the leaching rate of cement mortar were measured by phenolphthalein method [17, 24], as illustrated in Fig.3. It can be obtained from the figure that, the leaching rate of cement-mortar lining in $6 \mathrm{M}$ ammonium chloride solution is about 40 times of that in purified water, namely, its accelerating factor is 40 . 


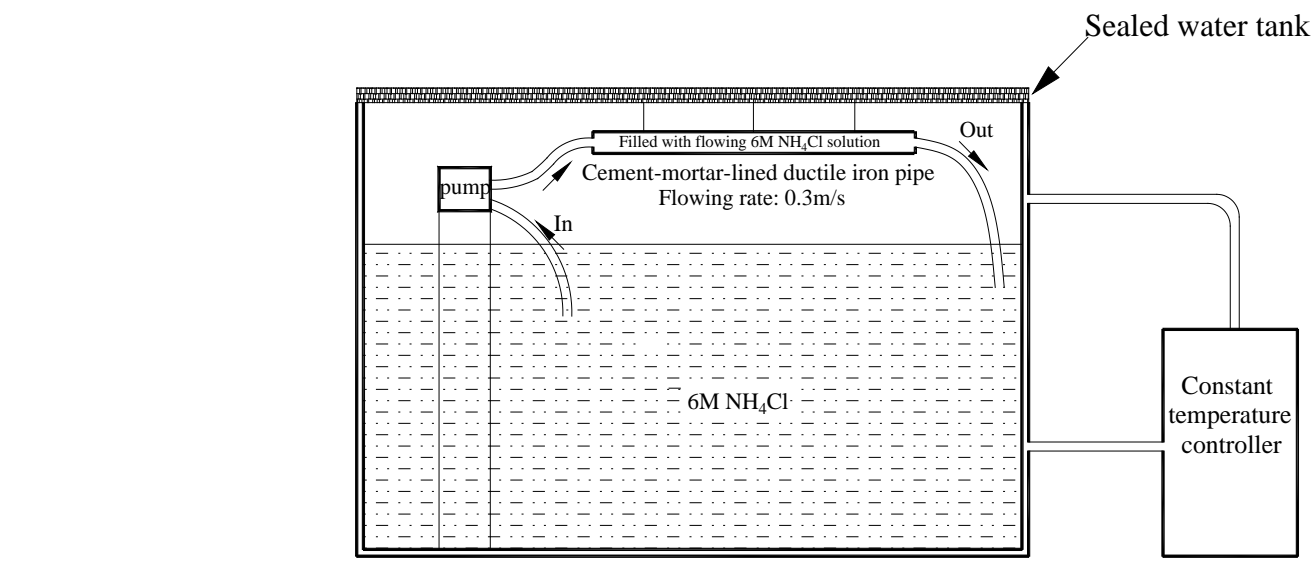

Fig.2 Experimental setup for simulating cyclic water transportion

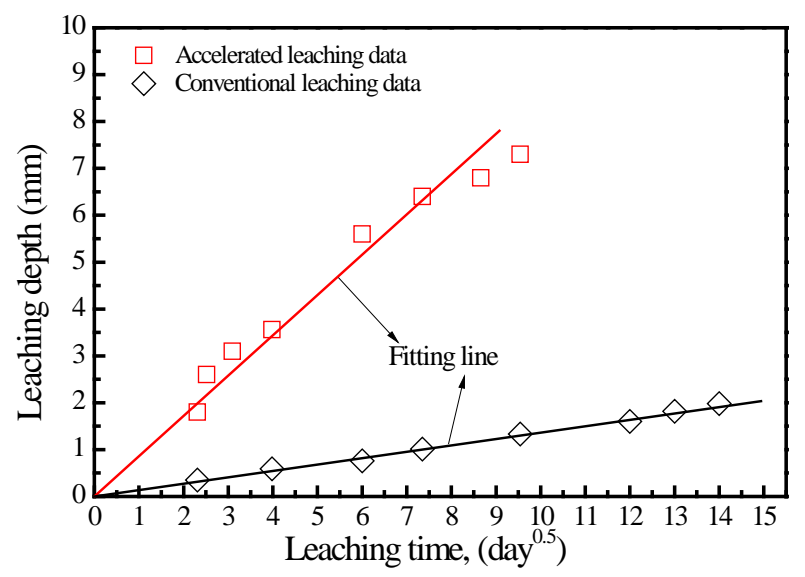

Fig.3 Leaching depth-time curves of cement-mortar specimens in 6M ammonium chloride solution and purified water

\subsubsection{Sample preparation}

In the process of calcium leaching, the porosity, phase composition, and microstructure of cement-mortar lining in ductile iron pipe undergo different changes[25, 26], and the changes of these parameters can be measured by the saturation-drying weighing method, mercury intrusion porosimetry (MIP), X-ray diffraction (XRD) and the scanning electron microscope (SEM/BSE) to characterize the leaching behavior of the lining, and further analyze the influence of slag on its leaching process. The related measurement samples from the cement-mortar-lined ductile iron pipe specimen can be prepared according to the steps presented in Fig.4.

When the cement-mortar-lined ductile iron pipe specimen was respectively corroded for 0, 150, 300 and 450 days by the flowing ammonium chloride solution, the cyclic corrosion experiment was temporarily stopped to cut out a pipe ring with a height of $10 \mathrm{~mm}$ from the end of the specimen, as illustrated in Fig.4 and 5(a), and then, the experiment was continually performed to the expected corrosion time. In the meantime, some samples with the size of $10 \mathrm{~mm} \times 10 \mathrm{~mm} \times 18 \mathrm{~mm}$ were cut from the pipe ring to make the ESEM-BSE samples while the others were separated into the cement paste-and mortar- samples from the lining in the ring for MIP analysis and the preparation of XRD powder respectively, as shown in Fig.5 (b). The sample of cement paste was dried in the oven at $80^{\circ} \mathrm{C}$ for $4 \mathrm{~h}$, and then ground in the agate mortar so as to pass the 100 mesh size sieve. The obtained powder was used for XRD analysis. In addition, the 
samples with 10mm thickness (as shown in Fig.5(b)) for ESEM-BSE analysis were freeze-dried for 24 hours, and then impregnated with epoxy resin under vacuum. After the epoxy resin had hardened at $40^{\circ} \mathrm{C}$, the measured surface of samples were carefully ground on a rotary grinding/polishing machine with silicon carbide papers of different grades and polished with the different grade diamond pastes [27, 28], until no visible scratches were observed, then the samples were cleaned and stored in the vacuum dryer for the ESEM-BSE analysis. The completed sample is shown in Fig.5 (c). Table 4 lists the detailed information of the measured samples.

\section{Table 4}

The information of measured samples

\begin{tabular}{|c|c|c|c|c|}
\hline \multirow{2}{*}{ Specimen } & \multicolumn{2}{|l|}{ Sample } & \multirow{2}{*}{ Test methods } & \multirow{2}{*}{ Test time } \\
\hline & Name & Notation & & \\
\hline \multirow{5}{*}{$\begin{array}{l}\text { Slag-cement-mort } \\
\text { ar-lined ductile } \\
\text { iron pipe }\end{array}$} & Slag-cement mortar & SCML & ESEM-BSE & 0,150 and 450 days \\
\hline & \multirow{2}{*}{$\begin{array}{l}\text { Cement paste layer } \\
\text { sample }\end{array}$} & \multirow{2}{*}{ SCML-C } & Saturation-drying weighing method & $0,150,300$ and 450 days \\
\hline & & & MIP, XRD & 0 and 150 days \\
\hline & \multirow{2}{*}{ Mortar layer sample } & \multirow{2}{*}{ SCML-M } & Saturation-drying weighing method & $0,150,300$ and 450 days \\
\hline & & & MIP & 0 and 150 days \\
\hline \multirow{5}{*}{$\begin{array}{l}\text { Ordinary-cement } \\
\text {-mortar-lined } \\
\text { ductile iron pipe }\end{array}$} & Ordinary cement mortar & OCML & ESEM-BSE & 0,150 and 450 days \\
\hline & \multirow{2}{*}{$\begin{array}{l}\text { Cement paste layer } \\
\text { sample }\end{array}$} & \multirow{2}{*}{ OCML-C } & Saturation-drying weighing method & $0,150,300$ and 450 days \\
\hline & & & MIP, XRD & 0 and 150 days \\
\hline & \multirow{2}{*}{ Mortar layer sample } & \multirow{2}{*}{ OCML-M } & Saturation-drying weighing method & $0,150,300$ and 450 days \\
\hline & & & MIP & 0 and 150 days \\
\hline
\end{tabular}

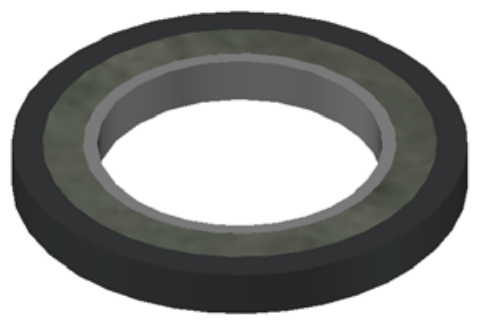

Pipe ring with height of $10 \mathrm{~mm}$
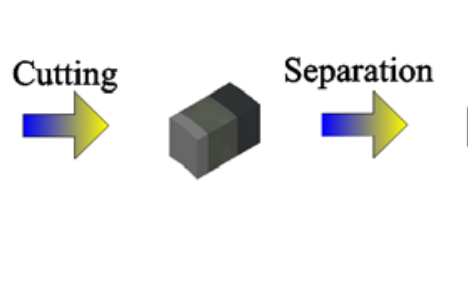

Cement past layer

Motar layer

Ductile iron layer

Fig. 4 Preparation steps of measured samples from the cement-mortar-lined ductile iron pipe specimen

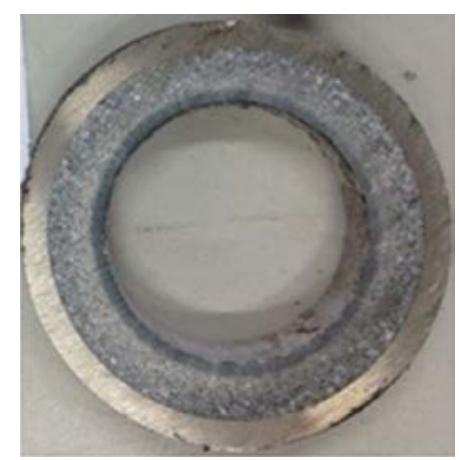

(a)


(b)

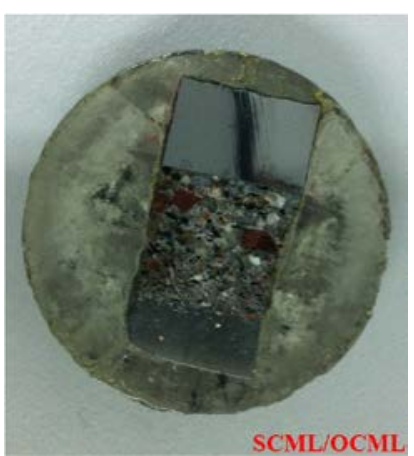

(c)

Fig. 5 Pictures of samples from cement-mortar-lined ductile iron pipe specimen 


\subsubsection{Test methods}

Saturation-drying weighing method [13, 29]: The mass of the saturated and dried cement paste and mortar samples were measured by the high-precision electronic weighing balance $(220 \mathrm{~V}, 50 \mathrm{~Hz})$ with maximum range of $200 \mathrm{~g}$ and accuracy of $0.1 \mathrm{mg}$. All samples were dried using the vacuum drying oven. After each immersion, the samples were removed from the container, and washed under flowing water. The mass of each saturated surface-dried sample $\left(\mathrm{m}_{\mathrm{s}}\right)$ was recorded, while the mass of samples suspended in distilled water $\left(\mathrm{m}_{\mathrm{x}}\right)$ was also measured by the balance with a built-in type. Finally, the samples were kept in a vacuum drying oven to dry to a constant weight at temperature of 60 obtained. The average porosity of sample $(\varphi)$ was calculated by the expression $\varphi=\left(m_{s}-m_{d}\right) /\left(m_{s}-m_{x}\right) \times 100 \%$.

MIP: The pore size distribution of the sample was measured by an Autopore IV 9500 automatic mercury intrusion porosimetry (MIP), which can generate a maximum pressure of 414MPa (60000psi) to evaluate a theoretical pore diameter of $0.006 \mu \mathrm{m}$. The MIP test was executed in two steps: the low pressure step first evacuates gases, fills the sample holder with mercury and performs porosimetry from about 3.5 (0.5psi) to 207kPa (30psi); the high pressure reaches pressures between $207 \mathrm{kPa}$ (30psi) and $241.5 \mathrm{MPa}$ (35000psi). Low and high pressure steps were always performed within a period of 3 hours. The contact angle and surface tension assumed for all tests were 130 degrees and 485 dynes/cm respectively. All tests were performed to achieve the manufacturer recommendation of a mercury stem volume between $25 \%$ and $85 \%$.

$\boldsymbol{X R \boldsymbol { D }}$ : The phase compositions in the powder sample from the leached specimen were analyzed by using Brucker X-ray diffractometer, while a LynxEye array detector with high efficiency was applied for X-ray diffractometer. The diffraction pattern was obtained with $\mathrm{Cu}-\mathrm{K} \alpha$ radiation operating at $40 \mathrm{kV}$ and $30 \mathrm{~mA}$. Scans were collected at $0.15 \mathrm{~s}$ per step and at a step size of $0.02^{\circ}$ over the range of $7^{\circ}$ to $80^{\circ} 2 \theta$. The Rietveld refinements of the measured XRD patterns [30-32] were performed to quantitatively analyze the phase composition of powder samples. The crystallographic information required for Rietveld refinement was taken from Crystallographic Information Files of Inorganic Crystal Structure Database [31].

ESEM-BSE: The prepared samples in Fig.5(c) were investigated using a Philips XL30 environmental scanning electron microscope (ESEM) with an energy spectrometer. The instrument was operated at $15 \mathrm{kV}$ accelerating voltage, beam current $20 \mathrm{~mA}, 0.3$ Torr pressure and at approximately $10 \mathrm{~mm}$ working distance for image acquisition. The electronic image of selected area with a resolution of $512 \times 400$ pixels and a total number of 32 frames was obtained by the back-scattered electron imaging, and in order to obtain the average Calcium-Silicon ratio of the selected area, the surface-scan mode of Energy Disperse Spectroscopy (EDS) was used to scan the electronic image.

\section{Results and discussion}

\subsection{Porosity}

Porosity is an important parameter characterizing the microstructure evolution of cement-based materials caused by calcium leaching in water environment, and it can reflect the leaching behavior of cement-based materials [33, 34]. Fig. 6 presents the porosity changes of the cement-mortar lining without and with slag with the leaching time. It can be obtained from the figure that, as a whole, the porosity of each sample increases with the leaching time, and its increase in cement paste layer samples OCML-C and SCML-C is significantly higher than that in mortar layer samples OCML-M and SCML-M. As shown in Fig.6 (a), at 0-150 days of the leaching experiment, the porosities of OCML-C and SCML-C increases respectively from $9.57 \%$ and $8.80 \%$ to $31.94 \%$ and $25.59 \%$. But, at $150-300$ days of the leaching experiment, the 
porosity increments of OCML-C and SCML-C are $11.23 \%$ and $8.8 \%$ respectively, and at $300-450$ days, there are respectively $9.14 \%$ and $6.75 \%$ porosity increments of OCML-C and SCML-C. Thus, for the cement paste layer, the porosity increment at every 150-days interval decreases with the leaching time, while the porosity increment of SCML-C with $40 \%$ slag is less than that of OCML-C without slag, especially from 0 to 150 days of the leaching experiment.

Because the mortar layer is located at the interior of the cement paste layer in the cement-mortar-lined ductile iron pipe, as illustrated in Fig.1(c), its calcium leaching is later than that of the cement paste layer under the flowing solution, and the porosity changes of mortar layer is different from that of cement paste layer, as presented in Fig.6(b). It can be obtained from Fig.6(b) that, at 0-150, 150-300 and 300-450 days of the leaching experiment, the porosity increments of OCML-M without slag are respectively $6.04 \%, 5.54 \%$ and $3.48 \%$, and the porosity increments of SCML-M with $40 \%$ slag are respectively $2.98 \%, 4.94 \%$ and $2.91 \%$. Thus, the porosity change of SCML-M with $40 \%$ slag is less than that of OCML-M without slag with the leaching times. It can be seen from these results that slag can slow down the calcium leaching process and effectively improve the leaching resistance of cement-mortar lining in ductile iron pipe. This is because, the slag improves the microstructure of the cement mortar, and in the hydration process of slag-cement-mortar system, the slag can consume calcium hydroxide generated by cement hydration and absorb calcium ions to cause the pozzolanic reaction, which can change the chemical compositions in the cement-mortar lining to generate C-S-H gel with more impact and stable microstructures in the alkaline environment [35, 36]. The generated C-S-H gel can fill the capillary pore and the space originally occupied by water, and it can reduce the porosity and calcium hydroxide content in the cement-mortar lining and slow down the calcium leaching process [37, 38].

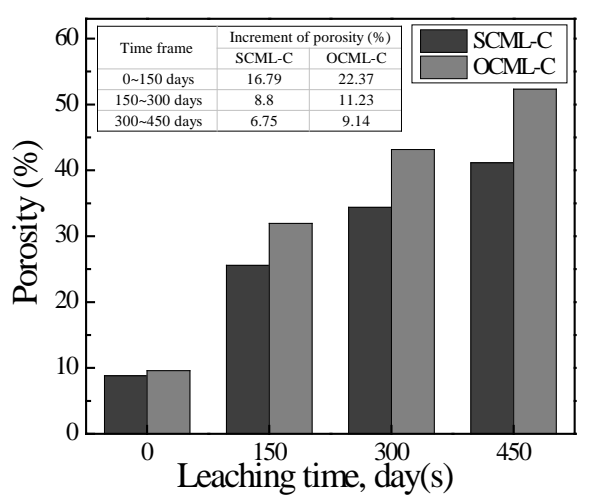

(a) Cement paste layer



(b) Mortar layer

Fig.6. Average porosity of cement-mortar lining

\subsection{Pore size distribution}

In order to obtain the pore size distribution in the cement-mortar lining at different leaching times, the mercury intrusion porosimetry (MIP) measurement was carried out to analyze the pore parameters of the unleached and 150-days-leached cement-mortar lining samples, such as the most probable pore diameter, pore size distribution, porosity, average diameter and critical pore size, as listed in Table 5. Fig.7 and Fig. 8 present the curves of cumulative pore size distribution (CPSD) and differential pore size distribution (DPSD) of the ordinary- and slag- cement-mortar lining at different leaching times. It can be obtained from Table 5 that, the porosities of the unleached SCML-C and SCML-M decrease from $9.57 \%$ and $13.58 \%$ to $8.80 \%$ and $9.31 \%$ respectively, and their most probable pore sizes (diameter) decrease from $17.11 \mathrm{~nm}$ and $32.39 \mathrm{~nm}$ to $12.25 \mathrm{~nm}$ and $11.05 \mathrm{~nm}$, while their critical pore sizes (diameter) decrease from $120.82 \mathrm{~nm}$ and $62.49 \mathrm{~nm}$ to $62.51 \mathrm{~nm}$ and $32.40 \mathrm{~nm}$, respectively. It can also be seen from Fig.8 that the unleached OCML-C 
and OCML-M have higher systematic CPSD than the samples SCML-C and SCML-M. And this result can also be observed on the DPSD curves in the figures. Thus, the mixture of slag can not only decrease the porosity, most probable pore size and critical pore size, but also improve the pore size distribution of the cement-mortar lining, and it can slow down the diffusion process of calcium ion.

After leaching for 150 days, the total porosity, most probable pore size (diameter) and critical pore size (diameter) of each sample have obvious increases, as shown in Table 5, and the pore volume in the pore size range of 0.01-0.5 $\mu \mathrm{m}$ have the most significant change, as illustrated in Fig.8. However, the degradation of pore structure in the slag-cement mortar lining is less than that in the ordinary-cement mortar lining. For example, the most probable pore size diameters of OCML-C without slag and SCML-C with $40 \%$ slag increased by $60.02 \mathrm{~nm}$ and $28.08 \mathrm{~nm}$, while the critical pore size diameters of OCML-C without slag and SCML-C with $40 \%$ slag increased by $106.19 \mathrm{~nm}$ and $88.53 \mathrm{~nm}$, respectively.

Based on the viewpoints of $\mathrm{Wu}[39,40]$ on the classifications of pore structures in cement-based materials, there are the harmless pores $(<20 \mathrm{~nm})$, less-harmful pores $(20-50 \mathrm{~nm})$, harmful pores $(50-200$ $\mathrm{nm})$ and much-harmful pores $(>200 \mathrm{~nm})$. On this basis, the pore size classification of the unleached and 150-days-leached cement-mortar lining samples are presented in Fig.9. It can be seen from the figure that, mixed with $40 \%$ slag in cement-mortar lining, its pore structure has a significant improvement, for example, the volume fraction of harmless pores in the cement paste layer increases from $23.77 \%$ to $42.45 \%$, and the volume fractions of harmful and much-harmful pores reduce from $20.84 \%$ and $39.49 \%$ to $10.85 \%$ and $31.20 \%$, respectively. In addition, after leaching for 150 days, the volume fraction of harmless pores decreases, while the volume fraction of less-harmful and harmful pores has a significant increase, so the pore structure of each sample degrades with the leaching time.

Table 5

Most probable pore size and critical pore size of samples

\begin{tabular}{ccccc}
\hline $\begin{array}{c}\text { Leaching time } \\
\text { (days) }\end{array}$ & Series & $\begin{array}{c}\text { Porosity } \\
(\%)\end{array}$ & $\begin{array}{c}\text { Most probable pore size, diameter, } \\
(\mathrm{nm})\end{array}$ & $\begin{array}{c}\text { Critical pore size, diameter } \\
(\mathrm{nm})\end{array}$ \\
& SCML-C & 8.80 & 12.25 & 62.51 \\
0 & OCML-C & 9.57 & 17.11 & 120.82 \\
& SCML-M & 9.31 & 11.05 & 32.40 \\
& OCML-M & 13.58 & 32.39 & 62.49 \\
& SCML-C & 25.59 & 40.33 & 227.01 \\
& OCML-C & 31.94 & 77.13 & 120.77 \\
& SCML-M & 12.29 & 50.34 & 151.04 \\
\hline
\end{tabular}

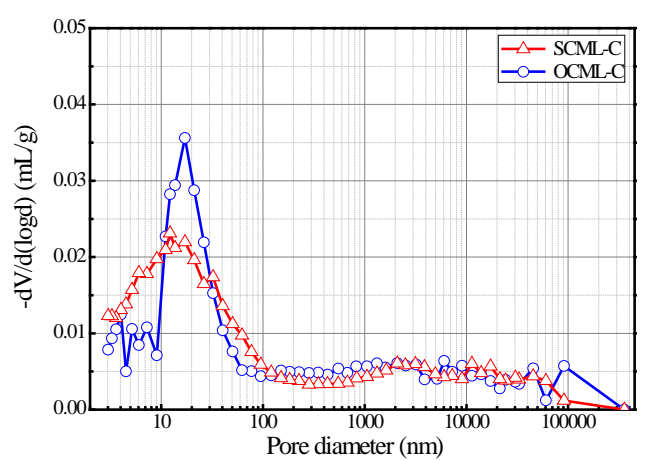

(a) Differential pore size distribution of cement layer

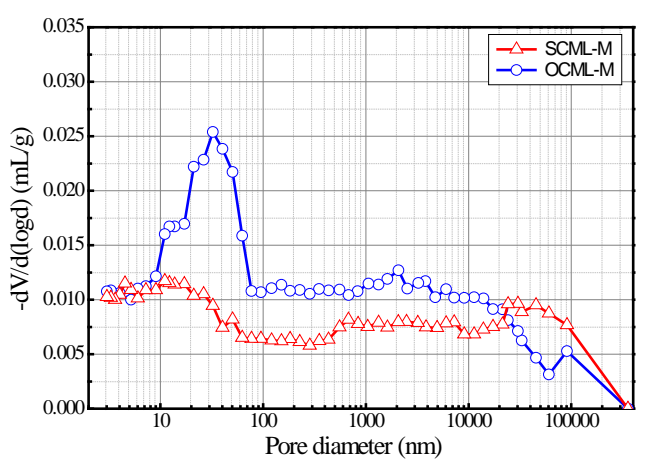

(b) Differential pore size distribution of mortar layer 


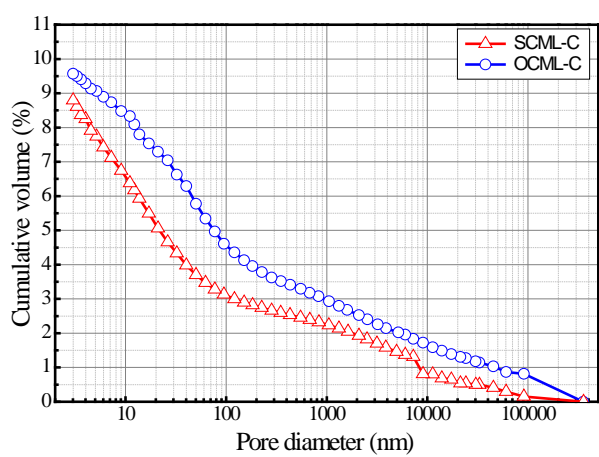

(c) Cumulative pore size distribution of cement layer

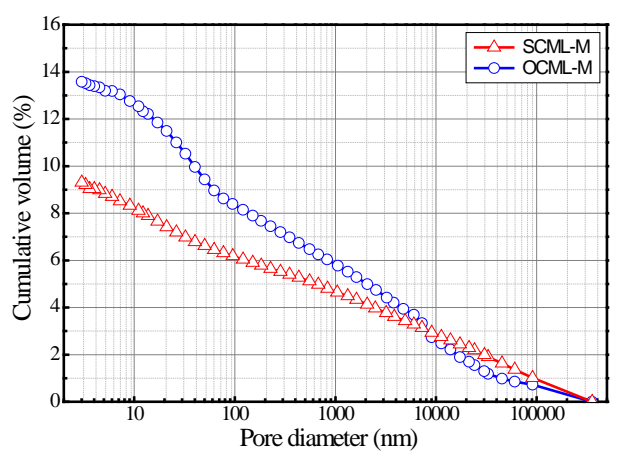

(d) Cumulative pore size distribution of mortar layer Fig.7. Pore size distributions of unleached samples with/without slag



(a) Differential pore size distribution of cement layer



(c) Cumulative pore size distribution of cement layer

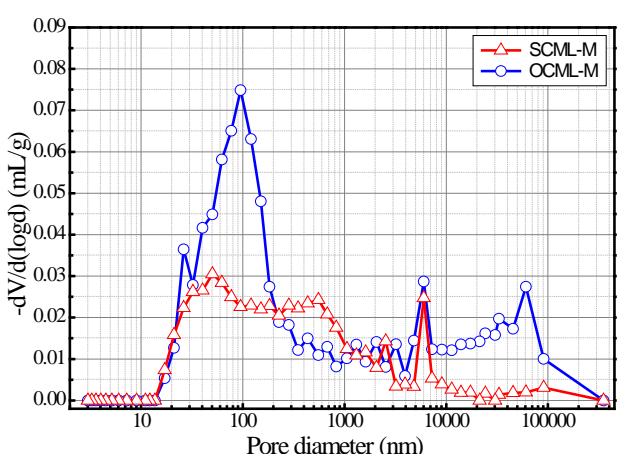

(b) Differential pore size distribution of mortar layer

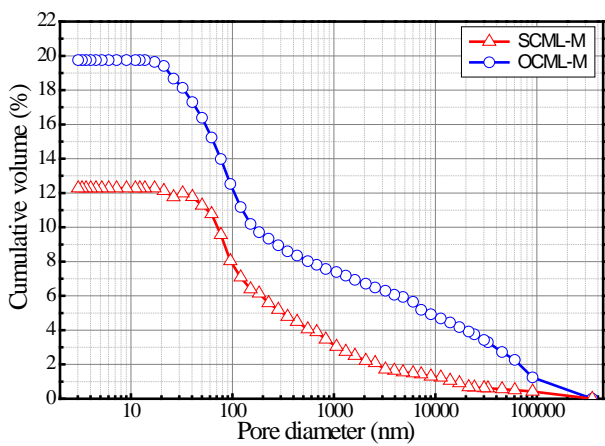

(d) Cumulative pore size distribution of mortar layer Fig.8. Differential and Cumulative pore size distributions of 150 days leached samples
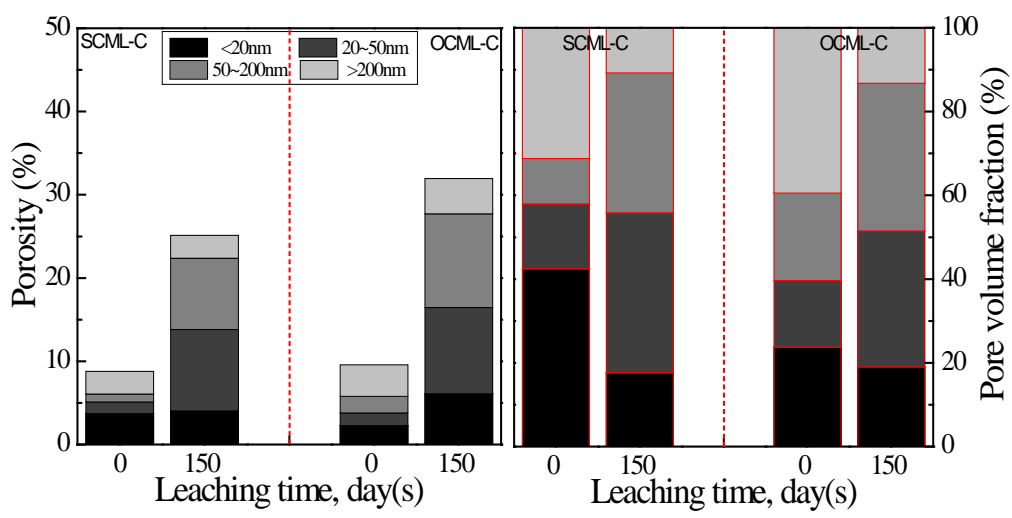

(a) Cement paste layer 

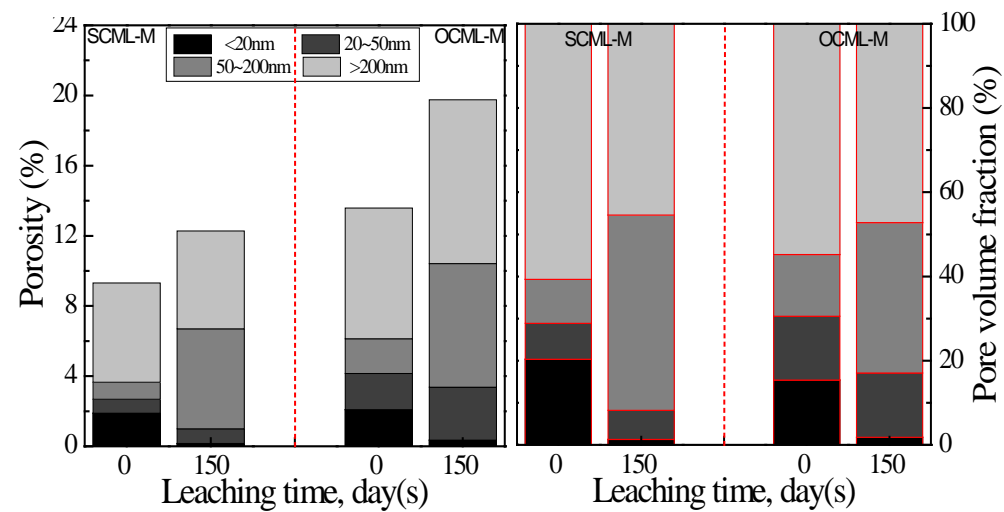

(b) Mortar layer

Fig.9. Pore volume distribution of cement-mortar lining

\subsection{Phase composition}

Fig.10 presents the XRD patterns of the unleached and 150-days-leached samples OCML-C and SCML-C, which are from the cement paste layers in ordinary- and slag- cement-mortar linings. It can be seen from the figure that, there are the obvious diffraction peaks of portlandite, ettringite and some unhydrated clinker minerals in the unleached samples OCML-C and SCML-C, and the intensity of diffraction peaks of portlandite in the OCML-C without slag is slightly higher than that in the SCML-C with $40 \%$ slag. Additionally,the traces of calcites, probably produced by the carbonation when the samples were prepared [41], can also be observed. After leaching for 150 days, the intense diffraction peaks at $2 \theta=$ $17.9^{\circ}$ and $34.2^{\circ}$ of portlandite disappear, and the diffraction peaks of belite and alite are also difficult to be observed in the OCML-C and SCML-C. In order to futher analyze the influence of slag on the leaching behavior of cement-mortar lining, the full profile Rietveld method[32, 42] was used to obtain the content of each phase in the samples OCML-C and SCML-C, and the quantitative results are listed in Table 6. It can be seen from the table that, after adding the slag in the cement-mortar lining, the content of portlandite decrease from $6.94 \%$ to $5.16 \%$, while the content of ettringite increase from $0.10 \%$ to $0.17 \%$. After leaching for 150 days, there is no traces of portlandite in OCML-C without slag, but a little of portlandite is measured in SCML-C with $40 \%$ slag. However, ettringite has a slight increase from $0.10 \%$ and $0.17 \%$ to $0.14 \%$ and $0.22 \%$ in OCML-C and SCML-C respectively, and this result is also reported by Faucon [43]. Thus, the addition of slag results in the increase of the ettringite content and the reduction of the calcium hydroxide content $[38,44]$, and consequently slow down the calcium leaching process of cement-mortar lining.

Additionally, as seen from Table 6, after leaching for 150 days in $6 \mathrm{M}$ ammonium chloride solution, the main phase compositions in the samples OCML-C and SCML-C are calcite, ettringite, belite, tricalcium aluminate and brownmillerite, and they are similar to the resluts from the leaching experiment on 3-mm-thick cement paste specimen immersed into deionized water for more than 10 years [45-47]. It shows that the change of phase composition of the cement paste in $6 \mathrm{M}$ ammonium chloride solution is consistent with that of the cement paste in deionized water, and there are no new crystal phases in the leaching process of cement paste immersed into ammonium chloride solution. Thus, the calcium leaching behavior of cement-mortar lining in ammonium chloride solution can be used to simulate that in deionized water, but its leaching rate in ammonium chloride solution is far more than that in deionized water. 


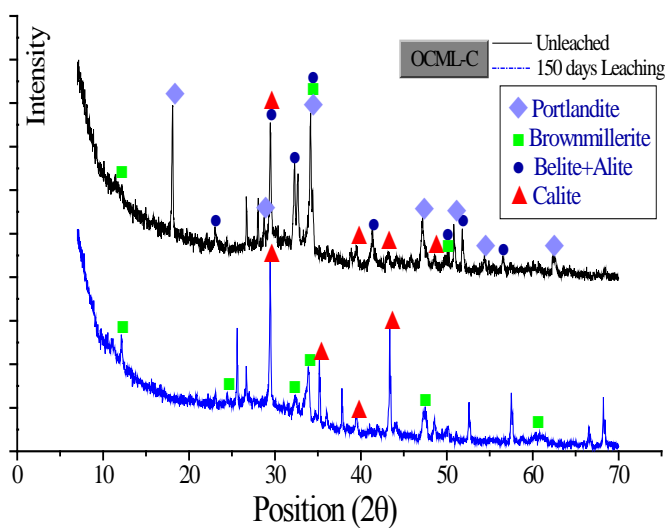

(a) OCML-C sample

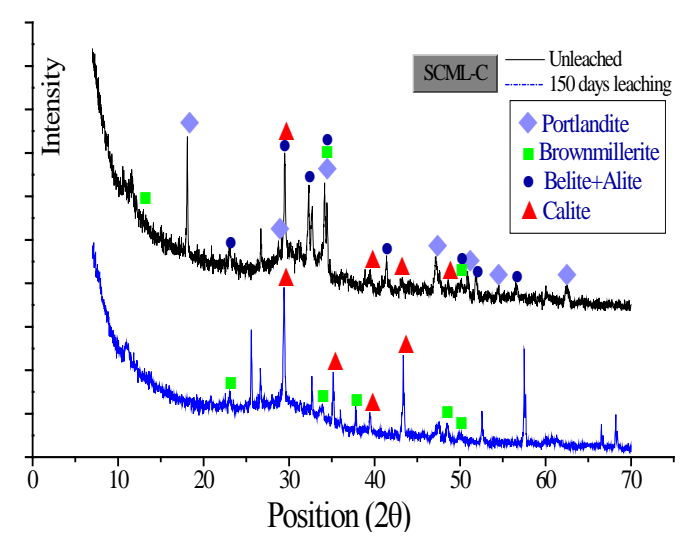

(b) SCML-C sample

Fig.10. XRD patterns of unleached and leached samples

\section{Table 6}

315 XRD- Rietveld results of samples- $10 \%$ internal standard $\mathrm{Al}_{2} \mathrm{O}_{3}$ was added to the mixtures

\begin{tabular}{ccccc}
\hline \multirow{2}{*}{ Phases } & \multicolumn{2}{c}{ unleached } & \multicolumn{2}{c}{150 days leaching } \\
& SCML-C & OCML-C & SCML-C & OCML-C \\
\hline Portlandite & $5.16 \%$ & $6.94 \%$ & $0.86 \%$ & - \\
Calcite & $5.59 \%$ & $6.99 \%$ & $5.46 \%$ & $6.40 \%$ \\
Ettringite & $0.17 \%$ & $0.10 \%$ & $0.22 \%$ & $0.14 \%$ \\
Belite & $9.11 \%$ & $6.99 \%$ & $1.66 \%$ & $1.03 \%$ \\
Alite & $14.94 \%$ & $12.01 \%$ & $0.83 \%$ & $0.80 \%$ \\
Tricalcium aluminate & $0.55 \%$ & $1.06 \%$ & $0.25 \%$ & $1.23 \%$ \\
Brownmillerite & $8.92 \%$ & $6.82 \%$ & $3.39 \%$ & $8.43 \%$ \\
Hydrogarnet & $0.85 \%$ & $0.24 \%$ & $0.70 \%$ & $1.46 \%$ \\
Gypsum & $2.61 \%$ & $0.59 \%$ & $1.09 \%$ & $0.33 \%$ \\
Bassanite Bezou & - & $0.33 \%$ & $0.33 \%$ & $0.14 \%$ \\
Ca-langbeinite & $0.47 \%$ & $1.20 \%$ & - & - \\
Aphthitalite & $2.01 \%$ & $0.66 \%$ & $0.55 \%$ & $0.45 \%$ \\
Thenardite & $1.76 \%$ & $1.49 \%$ & $0.57 \%$ & $0.08 \%$ \\
Hydrocalumite & - & - & $2.87 \%$ & $1.91 \%$ \\
\hline
\end{tabular}




\section{4. $\mathrm{Ca} / \mathrm{Si}$}

Generally, the phases of calcium and silicon in cement-based materials can be dissolved to calcium ions and silicate ions in water environments, but the solubility of silicon phase is far less than that of calcium phase in the pore solution. Therefore, in order to conveniently characterize calcium leaching process, the influence of silicon dissolution on the calcium leaching behavior is not considered, so the change of Calcium-Silicon ratio (Ca/Si) can characterize the calcium leaching behavior of cement-mortar lining in the flowing solution [19]. Fig.11 presents the SEM microstructure, EDS spectrum, element content and Ca-Si ratio at $1.5 \mathrm{~mm}$ depth of in the unleached samples OCML and SCML, which is located in cement paste layer, and the time-varying $\mathrm{Ca} / \mathrm{Si}$ at the different depths of the OCML and SCML is presented in Fig. 12. it can be seen from the figures that, the $\mathrm{Ca} / \mathrm{Si}$ in the unleached SCML is lower than that in the unleached OCML, and both of them have a gradual decrease with the leaching time. However, after accelerated leaching for 450 days, the $\mathrm{Ca} / \mathrm{Si}$ of the OCML and SCML at 1.5mm depth decreases from 2.8 and 3.1 to an even value of 0.8 , respectively, which indicates that the calcium leaching degree of the SCML is smaller than that of the OCML. This is because, after the partial replacement of cement by slag, the cement content in lining has a decrease, and the calcium oxide in slag is lower than that in cement, as shown in Tables 1 and 2, so the $\mathrm{Ca} / \mathrm{Si}$ in the unleached SCML is smaller than that of the unleached OCML. The mixture of $40 \%$ slag results in the reduction of the $\mathrm{Ca} / \mathrm{Si}$ and calcium hydroxide in cement-mortar lining, and causes the increase of its microstructure and compactness, as illustrated in Fig.6 and Fig.9. These can slow down the calcium leaching process and enhance the leaching resistance of the lining. In addition, the changes of $\mathrm{Ca} / \mathrm{Si}$ with the leaching time at $3.0 \mathrm{~mm}, 7.5 \mathrm{~mm}$ and $11.0 \mathrm{~mm}$ depths of the samples OCML and SCML are similar to that at $1.5 \mathrm{~mm}$ depth, as shown in Fig.12(b), (c) and (d).
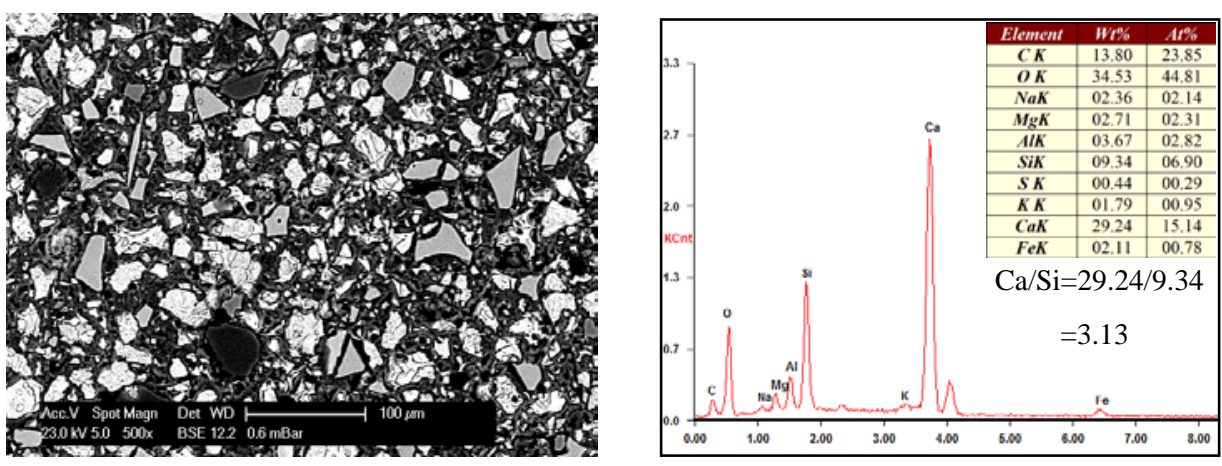

(a) OCML sample
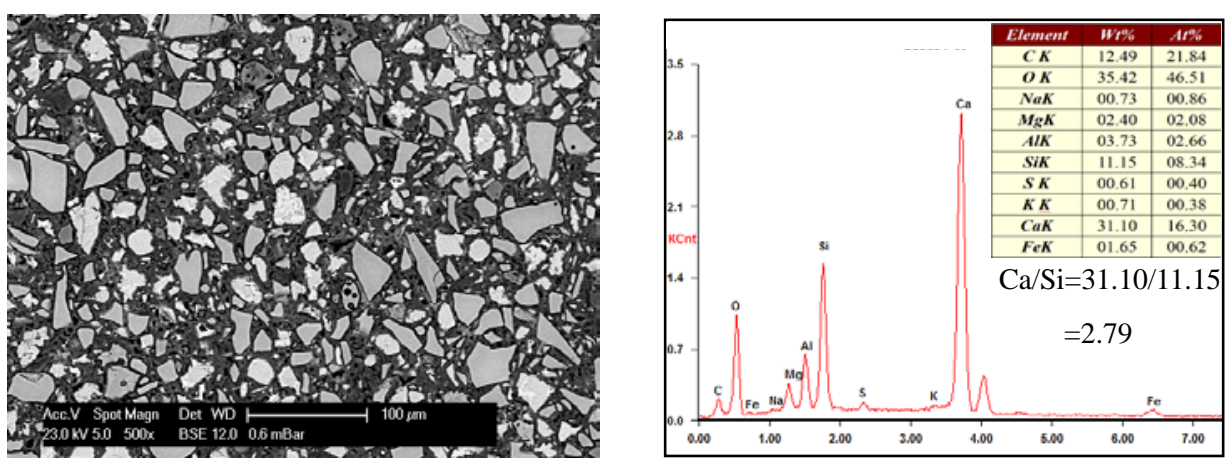

(b) SCML sample

Fig.11. SEM photo, EDS spectrum and element content at 1.5mm depth of unleached OCML and SCML samples 


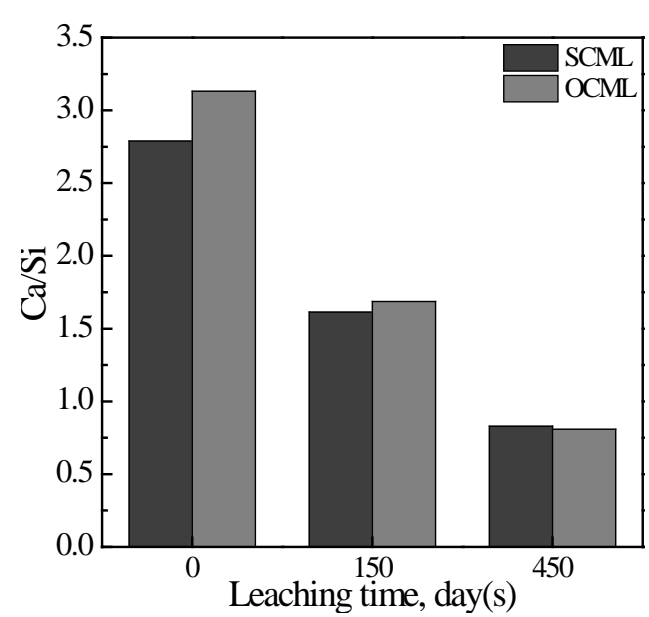

(a) Depth $1.5 \mathrm{~mm}$

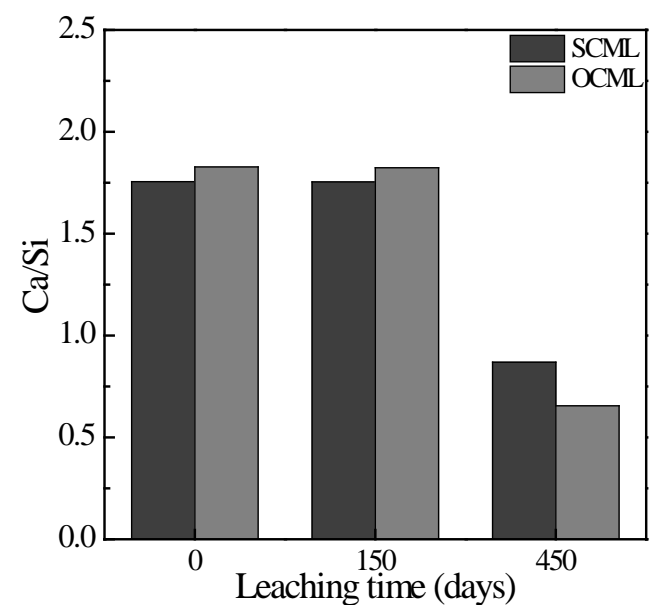

(c) Depth $7.5 \mathrm{~mm}$

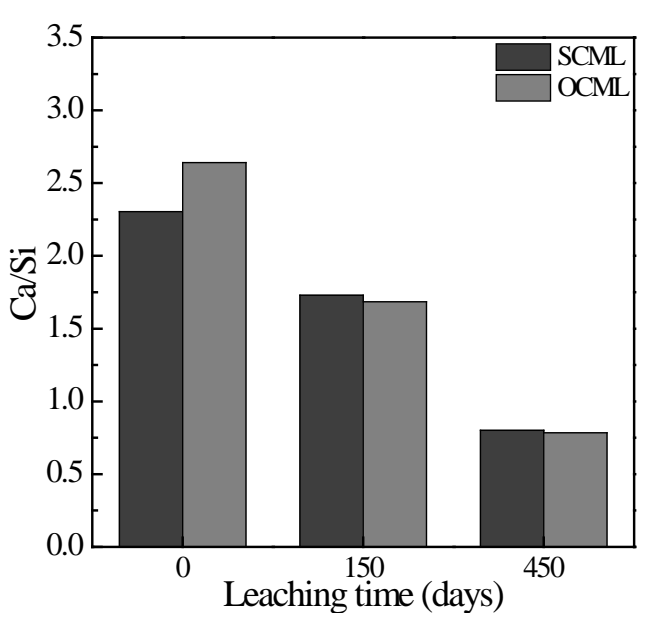

(b) Depth $3.0 \mathrm{~mm}$

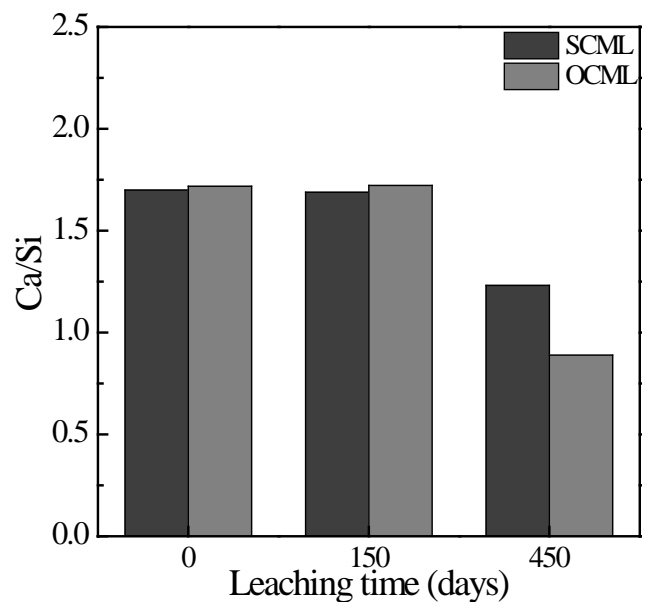

(d) Depth $11.0 \mathrm{~mm}$

Fig.12. Changes of $\mathrm{Ca} / \mathrm{Si}$ at different depths of the SCML and OCML samples with leaching time

\section{Conclusion}

This paper designs two kinds of specimen of the ductile iron pipe, lined with ordinary- and $40 \%$ slagcement mortar, and an accelerated leaching experiment on the specimens was carried out to investigate the influence of slag on the calcium leaching behavior of cement-mortar lining in the ductile iron pipe under $6 \mathrm{M}$ ammonium chloride solution with the flowing rate of $0.3 \mathrm{~m} / \mathrm{s}$. By using the saturation-drying weighing method, MIP, XRD and ESEM-BSE, the changes of some parameters with the leaching time, such as porosity, pore size distribution, phase composition and $\mathrm{Ca} / \mathrm{Si}$, were measured to analyze the influence of slag on the calcium leaching process of cement-mortar lining. Some conclusions are obtained. Firstly, the porosity, calcium hydroxide content and $\mathrm{Ca} / \mathrm{Si}$ of the unleached slag-cement-mortar lining are lower than that of ordinary cement-mortar lining. Secondly, in the calcium leaching process, the compactness, calcium hydroxide content and $\mathrm{Ca} / \mathrm{Si}$ of ordinary- and slag- cement-mortar linings decrease with the leaching time, but the decrease rate of cement-mortar lining with $40 \%$ slag is lower than that without slag. Finally, the addition of slag in cement-mortar lining can reduce its microstructure deterioration in the leaching process, and improve its calcium leaching resistance in ductile iron pipes. 


\section{Acknowledgements}

This study is financially supported by National Science Foundation of China (51378262) and Jiangsu Province Science Foundation (BK20141396).

\section{References}

[1] H.J. Kocks, W. Siedlarek

Zementmörtelauskleidungen von Trinkwasserleitungsrohren aus Guss und Steahl

Mater. Corros., 53 (2002), pp. 546-559

[2] P. Soukatchoff, J. Baron, L. Lessirard

Cement-based materials used in drinking water pipe systems

Water Sci. Technol., 1 (2001), pp. 227-236

[3] S.A.S. El-Hemaly, H.A.M. Abdallah, M.F. Abadir, H.H. El Sersy

Evaluation of the internal high alumina cement mortar lining of ductile cast iron pipes used in sewage transportation

Mater. Design, 29 (2008), pp. 1280-1283

[4] A.R. Mukhopadhyay, A.K. Das

Introduction of statistical process control system in a ductile iron pipe manufacturing plant for export promotion

Total Quality Management and Business Excellence, 16 (2005), pp. 861-876

[5] N.K. Blute, M.J. Mcguire, N. Wwst, N. Voutchkov, P. Maclaggan, K. Reich Integration of desalinated seawater into a distribution system: A corrosion pilot study Journal Awwa (2008), pp. 117-131

[6] Q. Guo Increases of lead and chromium in drinking water from using cement-mortar-lined pipes: Initial modeling and assessment

J. Hazard. Mater., 56 (1997), pp. 181-213

[7] H.F.W. Taylor

Cement chemistry

Academic Press(1990)

[8] F. Agostini, Z. Lafhaj, F. Skoczylas, H. Loodsveldt Experimental study of accelerated leaching on hollow cylinders of mortar Cement Concrete Res., 37 (2007), pp. 71-78

[9] A. Sander, B. Berghult, A.E. Broo, E.L. Johansson, T. Hedberg Iron corrosion in drinking water distribution systems - the effect of $\mathrm{pH}$, calcium and hydrogen carbonate Corros. Sci., 38 (1996), pp. 443-455

[10] H.S. Ajeel SA

Ductile and gray cast irons deterioration with time in various $\mathrm{NaCl}$ salt concentrations

Eng Technol, 26 (2008), pp. 1487-1492

[11] K. Haga, M. Shibata, M. Hironaga, S. Tanaka, S. Nagasaki

Silicate anion structural change in calcium silicate hydrate gel on dissolution of hydrated cement J. Nucl. Sci. Technol., 39 (2002), pp. 540-547 
[12] R. Taylor, I.G. Richardson, R.M.D. Brydson Composition and microstructure of 20-year-old ordinary Portland cement-ground granulated blast-furnace slag blends containing 0 to $100 \%$ slag Cement Concrete Res., 40 (2010), pp. 971-983

[13] J. Jain, N. Neithalath

Analysis of calcium leaching behavior of plain and modified cement pastes in pure water Cement Concrete Comp., 31 (2009), pp. 176-185

[14] R. Liu, B. Zhang, P. Yan, Le Li Microstructural variation of hardened cement-slag pastes leached by soft water Journal of The Chinese Ceramic Society (2013), pp. 1487-1492

[15] F.H. Heukamp, F.J. Ulm, J.T. Germaine Mechanical properties of calcium-leached cement pastes: Triaxial stress states and the influence of the pore pressures Cement Concrete Res., 31 (2001), pp. 767-774

[16] H. Yang, L. Jiang, Y. Zhang, Q. Pu, Y. Xu Predicting the calcium leaching behavior of cement pastes in aggressive environments Constr. Build. Mater., 29 (2012), pp. 88-96

[17] K. Wan, Y. Li, W. Sun Experimental and modelling research of the accelerated calcium leaching of cement paste in ammonium nitrate solution Constr. Build. Mater., 40 (2013), pp. 832-846

[18] Q. Phung, N. Maes, D. Jacques, G. Schutter, G. Ye Microstructural and permeability changes due to accelerated Ca leaching in ammonium nitrate solution Concrete Solutions (2014), pp. 431-438

[19] K. Wan, L. Li, W. Sun Solid - liquid equilibrium curve of calcium in $6 \mathrm{~mol} / \mathrm{L}$ ammonium nitrate solution Cement Concrete Res., 53 (2013), pp. 44-50

[20] K. Nakarai, T. Ishida, K. Maekawa Modeling of calcium leaching from cement hydrates coupled with Micro-Pore formation J. Adv. Concr. Technol., 4 (2006), pp. 395-407

[21] A.M. Forster, E.M. Szadurski, P.F.G. Banfill Deterioration of natural hydraulic lime mortars, I: Effects of chemically accelerated leaching on physical and mechanical properties of uncarbonated materials Constr. Build. Mater., 72 (2014), pp. 199-207

[22] Z.T. Bo, S.Y. Qi, L. Jun, C.J. Tao, K.X. Cheng, S.G. Bin, L.Z. Yi, F.Y. Gang, X. Jie, L.Z. Rong, L.J. Feng, T.H. Qing

Patent for coating the internal surface of a conduit, method and machine(CN201320723178.X), (2013)

[23] S. Kamali, M. Moranville, S. Leclercq

Material and environmental parameter effects on the leaching of cement pastes: Experiments and modelling Cement Concrete Res., 38 (2008), pp. 575-585

[24] Q.T. Phung, N. Maes, D. Jacques, G. De Schutter, G. Ye Investigation of the changes in microstructure and transport properties of leached cement pastes accounting for mix composition Cement Concrete Res., 79 (2016), pp. 217-234 
[25] S.H. Florian Häusler

An example of the sustainable protection offered by cement mortar linings in ductile cast iron drinking water pipelines

Ductile Iron Pipe Systems, 49, pp. 16-20

[26] F. Han, R. Liu, P. Yan

Effect of fresh water leaching on the microstructure of hardened composite binder pastes

Constr. Build. Mater., 68 (2014), pp. 630-636

[27] N.C. Collier, J.H. Sharp, N.B. Milestone, J. Hill, I.H. Godfrey

The influence of water removal techniques on the composition and microstructure of hardened cement pastes

Cement Concrete Res., 38 (2008), pp. 737-744

[28] M. Ba, C. Qian, X. Guo, X. Han

Effects of steam curing on strength and porous structure of concrete with low water/binder ratio

Constr. Build. Mater., 25 (2011), pp. 123-128

[29] R. CPC

Absorption of water by immersion under vacuum

Mater. Struct., 17 (1984), pp. 391-394

[30] Rodríguez-carvajal

A program for Rietveld refinement and pattern matching analysis

(1990)

[31] H.K. Choudhary, R. Kumar, M.E. Panzi, S. Matteppanavar, B.N. Sherikar

Observation of phase transformations in cement during hydration

Constr Build Materi, 101 (2015), pp. 122-129

[32] D.E. Cox

The Rietveld method. (IUCr Monograph on Crystallography, No. 5) edited by R. A. Young

J. Appl. Crystallogr., 27 (2007), pp. 440-441

[33] K. Haga, S. Sutou, M. Hironaga, S. Tanaka, S. Nagasaki

Effects of porosity on leaching of Ca from hardened ordinary Portland cement paste

Cement Concrete Res., 35 (2005), pp. 1764-1775

[34] K. Wan, Q. Xu, L. Li, W. Sun

3D porosity distribution of partly calcium leached cement paste

Constr. Build. Mater., 48 (2013), pp. 11-15

[35] I.G. Richardson, G.W. Groves

Microstructure and microanalysis of hardened cement pastes involving ground granulated blast-furnace slag

J. Mater. Sci., 27 (1992), pp. 6204-6212

[36] A.M. Radwan, E.A. Elalfi, R.M. Osman

Characteristics of Portland cement pastes with high replacement of slag

J Eng Appl Sci, 7 (2012), pp. 338-344

[37] W. Chen, H.J.H. Brouwers

The hydration of slag, part 1: Reaction models for alkali-activated slag

J. Mater. Sci., 42 (2007), pp. 428-443

[38] A. Fernández-Jiménez, F. Puertas

Alkali-activated slag cements: Kinetic studies

Cement Concrete Res., 27 (1997), pp. 359-368 
[39] Z.W. Wu

An approach to the recent trends of concrete science and technology

J Chin Ceram Soc (1979)

[40] J. Wang, D. Niu, S. Ding, Z. Mi, D. Luo

Microstructure, permeability and mechanical properties of accelerated shotcrete at different curing age Constr. Build. Mater., 78 (2015), pp. 203-216

[41] K. Haga, M. Shibata, M. Hironaga, S. Tanaka, S. Nagasaki Change in pore structure and composition of hardened cement paste during the process of dissolution Cement Concrete Res., 35 (2005), pp. 943-950

[42] K.L. Scrivener, T. Füllmann, E. Gallucci, G. Walenta, E. Bermejo

Quantitative study of Portland cement hydration by X-ray diffraction/Rietveld analysis and independent methods

Cement Concrete Res., 34 (2004), pp. 1541-1547

[43] F.A.R.C. P. Faucon

Deterioration mechanisms of cement paste under water attack

(1998), pp. 123-132

[44] E. Rozière, A. Loukili, R. El Hachem, F. Grondin

Durability of concrete exposed to leaching and external sulphate attacks

Cement Concrete Res., 39 (2009), pp. 1188-1198

[45] I. Natali Sora, R. Pelosato, D. Botta, G. Dotelli

Chemistry and microstructure of cement pastes admixed with organic liquids

J. Eur. Ceram. Soc., 22 (2002), pp. 1463-1473

[46] N. Marinoni, A. Pavese, M. Voltolini, M. Merlini

Long-term leaching test in concretes: An X-ray powder diffraction study

Cement Concrete Comp., 30 (2008), pp. 700-705

[47] J.T.B. Lagerblad

Leaching of 90-year old concrete mortar in contact with stagnant water

Swedish Cement and Concrete Research Institute, (1998) 